\title{
An Analytical Geographical Survey of Indicators for Determining the Levels of Noise Pollution، Due to Electric Generators، and Impaired Air Quality in The City of Ramadi
}

\author{
Qusay A. Hussain AL-Nemrawi \\ College of Education, University of Anbar, Iraq \\ ed.qusai.abd@uoanbar.edu.iq
}

\begin{abstract}
:
The current study was conducted on the city of Ramadi to find out the noise pollution represented by the sounds of generators on the residents of the city and its effect on the air purity in Ramadi city' in other words، this study aims to highlight the role of generators and their impact on increasing the level of noise pollution and air purity disturbance in the study area. Where the method of the analytical approach was followed، based on the analysis of the data obtained by the questionnaire forms of the generators owners as well as the residents of the study area. This research was divided into an introduction' a study on noise pollution and its concept and the second section dealt with the analysis and interpretation of the answers to the questionnaire forms that included (33) questions which were answered by the generators owners and the residents of Ramadi. Whereas the third section' where the sound and gas measurement device (SVAN955) (Sound Leved Metr) was used. (8) sites of various uses (commercial - residential - industrial - service) were selected and the levels of sounds were determined and compared with the relative determinants. It was clarified through the study that the city of Ramadi includes (453) generators distributing among the neighborhoods. As a result of the study that was conducted in the city of Ramadi، it was found that there are many complaints from residents of the study area which is considered $(80 \%)$ of the sample size because most of the generators do not contain a silencer. The study also showed that most of the pollutants resulting from the generators are discharged with the sewage network. The study highlighted that the generator sites are located near residential homes and schools and thus have high noise pollution as well as it is considered uncivilized phenomena being not surrounded by fences، isolators or trees. The study also indicated that most of the generators are not designed for this basis (modulated) with many problems and little cost. The study showed the effect of generators on the monthly income of families a as the study showed that the highest average family income is more than (550،000) dinars per month، and the average family spends more than (55) thousand dinars per month، this amount is not including household generators.
\end{abstract}

Keywords: $\quad$ Pollution; Noise; Environment; Clean Air; Ramadi City.

Crossref doi https://doi.org/10.51345/.v31i2.328.g182 


\section{مسح جغر افي تحليلي لمؤشرات تحديد مستويات التلوث الضوضائي بسبب المولدات واختلال نقاوة المواء في مدينة الرمادي$$
\text { أ.د.م. قصي عبد حسين النمر اوي }
$$$$
\text { كلية التربية، جامعة الأنبار، العراق }
$$ \\ ed.qusai.abd@uoanbar.edu.iq}

\section{ملخص البـحث}

تهدف الدراسة الى ابراز دور المولدات واثرها في زيادة مستوى التلوث الضوضائي واختلال نقاوة الهواء في المنطقة الدراسة حيث تم اتباع اسلوب المنهج التحليلي اعتمادآ على تحليل البيانات التي تم الحصول عليها بواسطة استحارات الأستبيان الخاصة بأصحاب المولدات وسكان منطقة الدراسة. قُسم البحث الى مقدمة ومبحث خاص بالتلوث الضوضائي ومفهومه، والمبحث الثاني تناول تحليل وتفسير اجابات استحارات الأستبيان التي ضمت (33) سؤالاً وتم الاجابة عليها من اصحاب المولدات وسكان مدينة الرمادي. اما في ما يتعلق بالمبحث الثالث حيث تم استخدام جهاز قياس الأصوات والغازات (SVAN955) وقد تم اختيار (8) مواقع متنوعة الأستعال (تجاري، سكني، صناعي، خدمي) وتم تحديد مستويات (Sound Leved Metr). الاصوات وتم مقارنتها مع المحددات النسبية. وقد تبين من هذه الدراسة ان مدينة الرمادي تضم ( 433 ) مولدة موزعة على الأحياء. ونتيجة الدراسة تبين ان هناك العديد من الشكاوي من سكان منطقة الدراسة وتعتبر (10٪) من حجم العينة لأن اغلب المولدات لا تحتوي على كاتم للصوت. واظهرت الدراسة ايضاً ان اغلب الملوثات الناتجة عن المولدات تصرف مع شبكة الصرف الصحي وابرزت الدراسة ان مواقع المولدات تقع بالقرب من الدور السكنية والمدارس وبذلك تكون ذات تلوث ضوضائي عالي وايضآ تكون ذات شكل غير حضاري لعدم احاطتها بأسيجة وعوازل او اشجار . وأوضحت الدراسة ايضآ ان اغلب المولدات غير مصممة لمذا الأساس (محورة) ذات مشاكل كثيرة وتكلفة قليلة. وقد بينت الدراسة تأثير المولدات على الدخل الشهري للعوائل حيث بينت الدراسة ان اعلى معدل لدخل الأسرة هو اكثر من ( 550000 ) دينار شهريآ ومعدل ما تنفقه الأسرة اكثر من (5 5 ) الف دينار شهريآ عدا ما يتم انفاقه على المولدات المنزلية. الكلمات المفتاحية: التلوث، التلوث الضوضائي، الرمادي، نقاوة الهواء، بيئة. Crossref doi) https://doi.org/10.51345/.v31i2.328.g182 
المقلدمة:

يعد الهو اء من اساسيات الحياة ،فأن انقطاعه لدقائق معدودة يعد كافيآ لهلاك الانسان لذا اصبح موضوع تلوث الهو اء في مقدمة الموضوعات التي تثير الجدل الحاد والنقاش المستمر ليس في أوساط العلم)ء المختصين فحسب بل في الأوساط والمؤسسات كافة وحتى بين المواطنين العاديين . وقد انشغل العديد من المختصين والمشرعين في بلدان العالم بسن القوانين المتعددة لأجل إلمحافظة على نظافة الهو اء والرقابة من تلوثه ولعل رجال الاعحال وأصحاب المصانع والمؤسسات الإنتاجية في مقدمة من يعنينهم الأمر لأنهم اول من يدفع الضرائب والغرامات التي تحملهم المسؤلية في النهاية . ان مايزيد موضوع تلوث الهواء خطورة تأتي في ضعف الوسائل العلمية والتنقنية المستخدمة للأقلال او التخلص منه رغم التقدم الأخير الحاصل اخيراً .ان العصور اللاحقة أصبحت اكثر وضوحآ عندما ازدادت معدلات نمو المدن و الصناعات .وعلينا ان نبين ان تلوث الهواء لا يسببه الانسان فقط وانما ينتج من الكوارث

الطبيعية كذلك كأنفجار البراكين والاعاصير واندلاع الحرائق في الغابات والعو اصف الغبارية وغيرها(1). وان الكشف عن ملوثات الهواء يقتظي استخدام أجهزة غاية في الدقة وذلك بسبب التراكيب المحسوسة لهذه الملوثات التي تقدر بيضعة أجزاء من المليون ppm او حتى اقل من ذلك لذا فأن مسألة تطوير واستخدام الأجهزة عالية الحساسية لملوثات الهواء تعتبر من اهم التحديات العلمية التي تواجه علماء البيئة والهندسة الكيمياوية ،وقد ظهر مؤخرآ عدد من هذه الأجهزة ذات الحساسية العالية والتي ترتبط بالحاسوب جعلت مهمة مراقبة تلوث الهواء بشكل افضل.

\section{مشكلة البـحث}

- - هل يتأثر سكان مدينة الرمادي بأصوات المولدات الكهربائية؟ - - هل ها تأثير على نقاوة هو اء مدينة الرمادي؟ - - هل هناك تباني مكاني لمستويات التلوث الضوضائي ونقاوة الهواء بين اجزاء مدينة الرمادي ؟ 


\section{فرضيـة البـحث}

تأثر سكان مدينة الرمادي بأصوات المولدات الكهربائية "وهناك تباين مكاني لتلوث الهو اء في مدينة الرمادي.

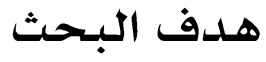

يهدف البحث المى ابراز دور المولدات الكهربائية واثرها في زيادة مستويات التلوث الضوضائي واختلال نقاوة الهو اء في منطقة الدراسة . اس

\section{منهجية البحثث}

اتبع البحث أسلوب المنهج التحليلي الكمي الذي يعتمد على تحليل البيانات التي تضمنتها استمارات الاستبيان الخاصة بأصحاب المولدات وسكان المدينة وتفسير القياسات الميدانية المختبرية ويقسم البحث المى مقدمة ومبحث خاص يتناول الضوضاء والمبحث الثاني تحليل وتفسير إجابات استمارات الاستبيان والتي ضمت (3 3 سؤال ثم الإجابات عليها أصحاب المولدات وسكان مدينة الرمادي .المبحث الثالث فيها استخدم جهاز قياس الأصو ات والغازات (sound level Meter) (SVAN955) وقد تم اختيار (8) مواقع متنوعة الاستعمال (تجاري- سكني- صناعي- خدمي) لتحديد فيها مستويات الأصوات ومن ثم استخدامها مع المحددات النسبية فضلا عن تلوث الهواء عن طريق قياس ثلاث عناصر رئيسية مهمة والمناطق المختلفة ومع اهم المواد العالقة مع اهم النتائج و التوصيات التي تم تحديدها بأستخدام GPS .

\section{منطقة الدراسة}

تقع مدينة الرمادي بحدودها الإدارية على الضفة اليمنى لنهر الفرات بين دائرتي عرض (22-33)(33 -37) شمالآ وبين خطي طول (44-43)(43-46) شرقآ عند الجزء الجنوبي الشرقي من محافظة الانبار وهي بموقعها أصبحت احدى المحطات المهمة على طريق القوافل بين بغداد وبلاد الشام(2). اما موقع المدينة على الحدود الدولية فهو قريب لكونها تشكل منفذآ خارجي للعراق قديمآ وحديثآ نحو سواحل البحر المتوسط 
عبر الطريق الذي يربط العراق بـ(سوريا-الأردن-السعودية) يحدها من الجنوب السعودية اما من الغرب

$$
\text { الادن وسوريا(3) انظر الخريطة (1) . }
$$
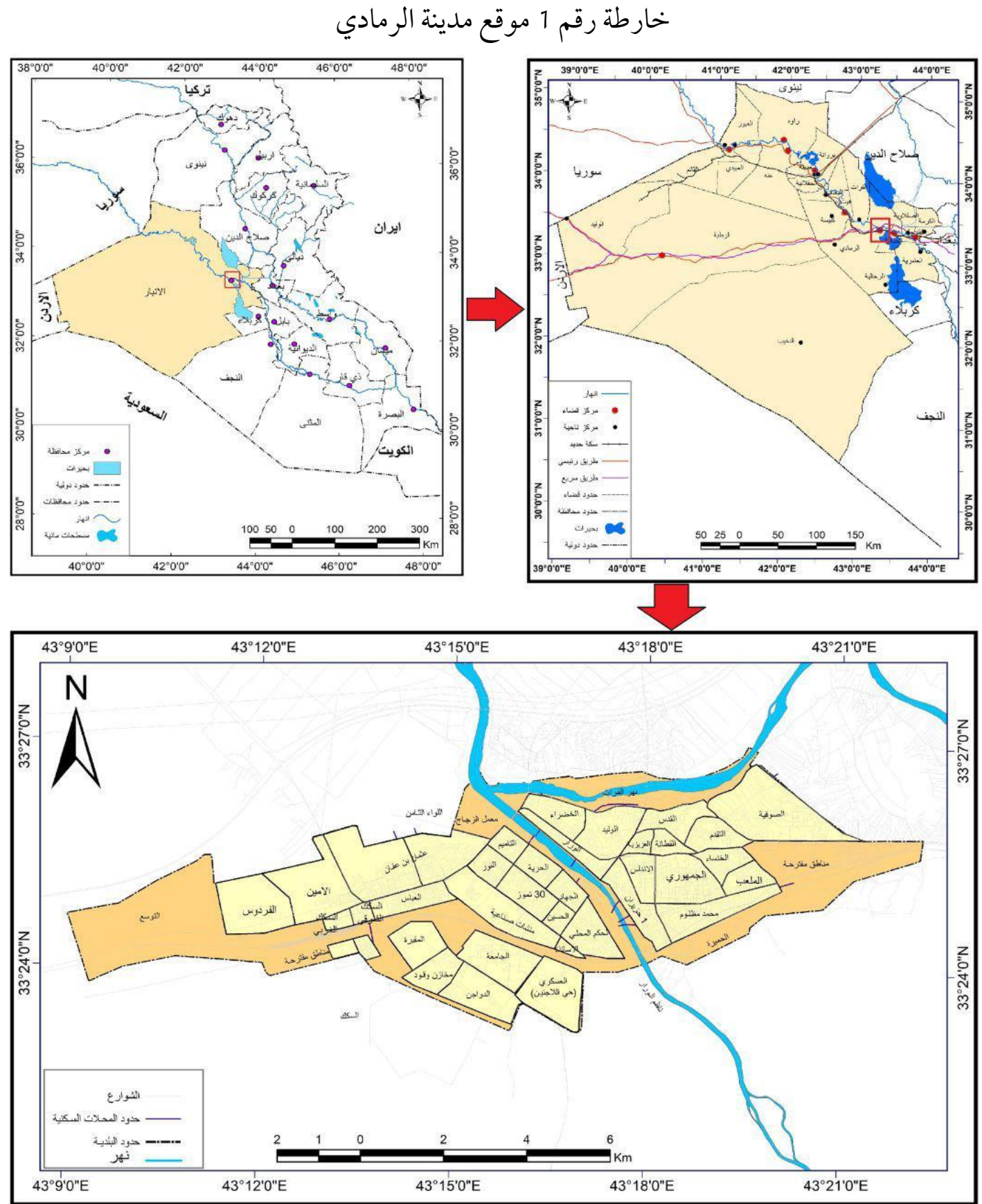

المصدر: جمهورية العراق، وزارة الري، الهياة العامة للمساحة، خريطة الانبار 2006. 


\section{التلوث الضوضائي}

\section{أولاًا: مفهوم التلوث الضوضائي}

التلوث الضوضائي هو ناتج عن الأصوات المؤثرة سلبا على الانسان ويعرف الصوت على انه تلك الموجات التي ها طابع الانتظام الموسيقي المتناسق وهنا تعريف اخر بأنه مؤثر خارجي يؤثر على الاذن فيسب بالاحساس بالسمع ويمكن القول ان كل جسم مهتز يشكل مصدر آ للصوت لأن اهتزاز جزيئات الهواء من حوله على شكل موجات تنتشر في جميع الاتجاهات وتعرف هذه الموجات بالموجات الصوتية وينقطع الصوت تمامآ عن توقف الجسم المهتز عن الاهتزاز(4).كما يعرف الضجيج :هو تلك الموجات التي ليس لها طابع الانتظام الموسيقي الموحد(5). ويعرف الضوضاء بأنه: تلك الأصوات غير المرغوب فيها نظرآ لزيادة حدتها

وشدتها وخروجها عن المئلوف من الأصوات الطبيعية التي اعتاد على سماعها كل من الانسان والحيوان(6).

ثانيًا : مصادر التلوث الضوضائي وطرق قياسه تنقسم مصادر التلوث الضوضائي الى:

\section{1- المصادر الطبيعية:}

وهي تلك المصادر التي تنتج من عوامل طبيعية ليس للأنسان او تقنياته دورآ فيها كالرعد والانفجارات البركانية والرياح والزلازل وامواج البحر العالية

أ-الرعد : هو اية من الايات الكونية التي تدل على وجود الله سبحانه وتعالى وهو احدى الظواهر الطبيعية التي تحدث عن ظروف معينة ومصاحبة لحدوث ظاهرة واية أخرى وهي ظاهرة البرق قال تعالى: لََّْْ كَصَيٍِّ

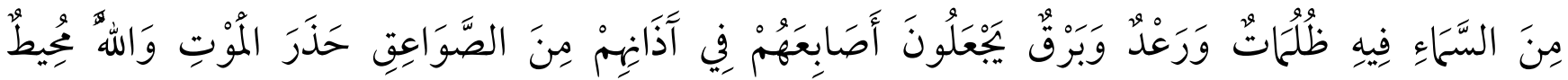

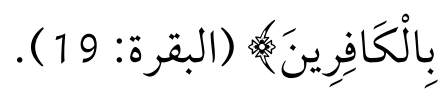
والرعد: هو عبارة صوت جلجلة وانفجار يحدث في طبقات الجمو نتيجة تفريغ شحنة كهربائية عالية جدآ وهو حدث خخيف يفزع منه الكبير قبل الصغير ويولد في الانسان شعور آبالخوف و الرهبة والهلع (7). 
ب- الرياح: هي الهو اء المتحرك بسرعة وتهب بمشيئة الله وارادته على هيئة تيارات هوائية تتحرك مندفعة من جهة المى أخرى فوق سطح الأرض وفي اثناء حركتها تدر اصواتاً تختلف شدتها حسب السرعة التي تتحرك فيها وبجانب الدمار الذي يمكن ان تسببه الريح والعواصف فأهها تحدث كذلك ضجيجاً وجلجلة هائلة تؤثر سلباً على الاذن.

ج-الانفجارات البركانية: تعد البراكين مظهراً من مظاهر حرارة باطن الأرض والتي توجد تحت غلاف الأرض الصخري وتمثل البراكين كارثة أرضية خاصة عند صوتها في الأراضي الزراعية او بالقرب منها حيث يؤدي الى اندفاع صهير البركان والمعروف (بالنجا) الم سطح الأرض الى دفن الأراضي الزراعية وتغطيتها بأكوام من الصخور البركانية وبالإضافة الى ذلك يصاحب حدوث انفجارات البركانية دوي هائل واصوات وانفجارات عالية. د- الزلازل: هو اهتزاز القشرة الأرضية في مكان ما من سطح الأرض وتتفاوت شدة الزلازل حسب قوة الاهتزاز وطبيعة القشرة الأرضية في منطقة الزلزال ويتعرض سطح الأرض بها عليه في تلك المناطق الى تموجات تسبب المى انهيار المباني والجمور وتشقق وتصدع سطح الأرض ويصاحب حدوث ذلك صدور أصوات عالية وضوضاء شديدة(8).

\section{2- المصادر البشريـة:}

يجدث التلوث الضوضائي عن النشاط الأنساني وهذا النشاط يؤدي المى وجود مصادر حادثة للضوضاء كالألأت والأدوات ووسائط النقل والمعامل. أ- وسائط النقل: استطاع الانسان بفضل ما ميزه الله به عن بقية المخلوقات من نعمة العقل واختراع وتصميم وبناء العديد من وسائط النقل البرية والبحرية والجوية فأذا تدبرنا الطريقة والوسيلة التي تنتقل بها اليوم بين المدن و البلاد والقارات من حيث السرعة والسهولة والراحة والأمان ولكن وبكل اسف فقد صاحب حركة هذه الوسائط وتشغيلها صدور أصوات عالية فلقد ازدمت الشوارع بوسائط النقل الحديثة بأنو اعها المختلفة 
وما تحدثه في اثناء سيرها من ضجيج ولقد امتد هذا الضجيج الى الجو من خلال حركة الطائرات التي زاد استخدامها بدرجة كبيرة في النصف الأخير من القرن العشرين سواء لنقل المسافرين او نقل البضائع وغيرها و الضوضاء الصادرة عن الطائرات يكون تأثيرها اكبر من الضوضاء الصادرة من وسائط النقل الأخرى فضلآ عن أصوات القطارات والسكك الحديدية الناتجة عنها تعتبر من المصادر المسببة في تحديد حجم الضوضاء الو اقعة على البيئة (9). ب- المدن المزدمة: والضوضاء فيها ناتجة عن حركة الناس وفعاليتهم كالموسيقى الصاخبة في الأفراح والحفلات والمناسبات المختلفة وكذلك الصادرة عن المنازل واستخدام الماكنات في اعحال الطرق والمباني. ج- دور السكن والمكاتب والمحال التجارية: اذ يصدر من هذا المصدر أصوات مختلفة منها صراخ الأطفال وصياح الكبار وأجهزة المذياع والتلفزيون وأجهزة التكييف وباقي الأجهزة المنزلية الأخرى(10). د- المصانع والحرف اليدوية الأخرى: يسبب هذا المصدر أنواع من الأصوات تسبب اضرار للعاملين في المصانع ويجب ان تكون هناك قو انين ومنظمات لحماية العمال فيها اما بالنسبة للحرف والورش الصناعية كالتجارة والحدادة وغيرها من الحرف اليدوية الأخرى فضلآ عما يحدثه الغاز المضغوط للهواء الذي يخرج فجأة ويحتك بالأجسام الصلبة(11).

جدول رقم 1 يوضح الحد الاقصى المسموح به لشدة الضوضاء في مناطق مختلفة / ديسبل

\begin{tabular}{|c|c|c|c|c|}
\hline 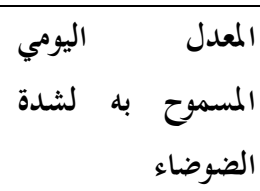 & 7ليلآ م 10م الى & 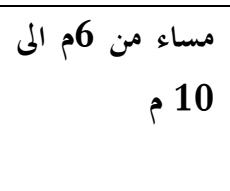 & كتى 6م من & نوع المنطقة \\
\hline $60-50$ & $55-45$ & $60-50$ & $65-55$ & الادارية وسط الملدينة \\
\hline 55-45 & $50-40$ & $55-45$ & $60-50$ & المناطق السمال التجارية \\
\hline
\end{tabular}




\begin{tabular}{|c|c|c|c|c|}
\hline $50-40$ & $45-35$ & $50-40$ & $55-45$ & المدينة المكاطق المنية في \\
\hline $45-35$ & $40-30$ & $45-35$ & $50-40$ & الضواحي السكنية \\
\hline $40-30$ & $35-25$ & $40-30$ & $45-35$ & المنيفة السكنية \\
\hline $65-55$ & $60-50$ & $65-55$ & $70-60$ & والمناطق $\quad$ الصناعات الثقيلة \\
\hline
\end{tabular}

المصدر: محمد احمد خليل ، ملاحق الهندسة البيئية والصحية ، دار الكتب العلمية للنشر والتوزيع،القاهرة 100 ، ص 38 .

\section{أولاً: منـاقشة استـمارة الأستبـيـان الخاصة بـالمولدات}

من خلال جدول رقم (1 ) نلاحظ اختلاف واضح في الأجابات وهذا تأكيد على ان اختيار موقع المولدات جميعاً لم يكن مصمم اساسآ لهذه الغاية وهذا ما أكدته إجابات العينة المختارة بنسبة وصلت الى (.8. 67 ) من المولدات تم اختيارها حسب حاجة الحي السكني أي (1 6 ) مولدة و( 49 ) مولدة تم تحوير موقعها بنسبة تصل الى (1\%32.9)

اما فيما يتعلق بجدول رقم (2) وما يتلق بالمساحة التي تشغلها المولدة وملحقاتها فكانت ما بين ( 5 م 2 ) بعدد

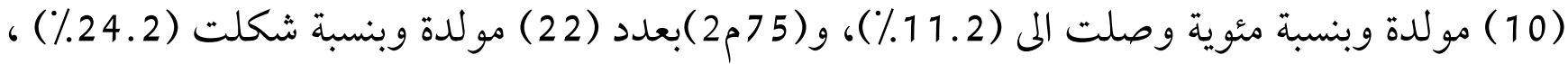
و(00 م2 ) وبعدد ( 25 ) مولدة وبنسبة مئوية (8. 87 (\%) والتي احتلت مساحة (100 م2 فأكثر) بعدد (33 ) مولدة وبنسبة (6.6 \% \% من حجم العينة المختارة . ومن تفسير نتائج جدول رقم (3 ) تبين لنا ان اعلى نسبة لقرب المولدة كانت بالقرب من الدور السكنية حيث بلغت (8. 87 \%) بواقع (16) مولدة كحا كانت بنسبة (4.5\%) بواقع (4) مولدة بالقرب من المراكز الصحية ، وكانت نسبة (7.7.) بالقرب من الخدمات الاجتحاعية بواقع (7)مولدات ، فيها كانت نسبة القرب من

$$
\text { المدارس (\%20) بعدد (120) ) مولدة. }
$$




\begin{tabular}{|c|c|c|c|c|}
\hline الجموع & تمح تحوير موقع & الموقع اسآ المصمم & حسب حاجة & الخيارات \\
\hline 90 & 29 & ------- & 61 & العدد \\
\hline$\% 100$ & 32.2 & ------- & 67.8 & $\%$ \\
\hline
\end{tabular}

\begin{tabular}{|c|c|c|c|c|c|}
\hline الجمموع & 1001 فأكثر & $p^{2} 80$ & $\rho^{2} 75$ & ${ }^{2}, 50$ & المساحة \\
\hline 90 & 33 & 25 & 22 & 15 & العدد \\
\hline$\% 100$ & 36.6 & 27.8 & 24.4 & 11.2 & $\%$ \\
\hline
\end{tabular}

\begin{tabular}{|c|c|c|c|c|c|}
\hline الجموع & مدرسة & خدمات & مركز صحي & دور سكنية & اسم الموقع \\
\hline 90 & 18 & 7 & 4 & 61 & العدد \\
\hline$\% 100$ & 20 & 77 & 4.5 & 67.8 & $\%$ \\
\hline
\end{tabular}

كما بين جدول رقم (5) ملائمة موقع المولدة لسكان الحي من حيث اثارة الضوضاء اذ استأثرت على نسبة وصلت (65.5\%) بعدد (579) مولدة يليها تأثير الأبخرة والغازات على السكان بنسبة وصلت الى (22.2\%)بعدد(20) مولدة، واخيراً تأثير الملوثات على شبكة الصرف الصحي بنسبة (3.3.1\%) وبعدد (11)

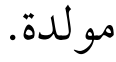




\begin{tabular}{|c|c|c|c|c|}
\hline الجمموع & شبكة الص الصرف & 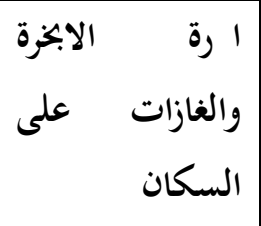 & ا رة الضوضاء & الا ر \\
\hline 90 & 11 & 20 & 59 & العدد \\
\hline$\% 100$ & 12.3 & 22.2 & 65.5 & $\%$ \\
\hline
\end{tabular}

اما فيما يخص جدول رقم (6) هناك (99 ) مولدة توجد أماكن خخصصة لطرح النفايات أي ما يعادل (7.78\%) من حجم العينة و(8.7٪) من حجم العينة تطرح نفايتها في الشوارع والسواقي بواقع (7) مولدات، اما مشكلة الصرف الصحي بو اقع (4)مولدات . جدول رقم (7) أماكن طرح ملوثات المولدة الكهربائية

\begin{tabular}{|c|c|c|c|c|}
\hline الجمموع & لطاكن ألفا ت لخصصة & طرحها في الشوارع & الصحي شبكة الصرف & من النفا تيب التخلص \\
\hline 90 & 79 & 7 & 4 & العدد \\
\hline$\% 100$ & 87.7 & 7.8 & 4.5 & $\%$ \\
\hline
\end{tabular}

اما فيها يخص معطيات جدول رقم (7) والتي وضحت إجابات السؤال الخاص بسعة المولدة الكهربائية بـ(KV) فكانت على نسبة لأكثر من (500KV) بنسبة (1 1 4 \%) ويعدد (7 3 ) مولدة تليها سعة (400KV) بنسبة مئوية وصلت الى (26.7\%) بواقع (24 ) مولدة فيما جاءت مولدات بسعة (350KV) بالمرتبة الثالثة بعدد (17) مولدة ونسبة مئوية وصلت الى (18.9.)، فيما جاءت مولدات سعة (250KV) بالمرتبة الأخيرة بواقع (12) 
مولدة وبنسبة مئوية (3.3 \%٪)وهذا يعكس حجم الملوثات الغازية المنبعثة من تشغيل هذه المولدات وخاصة ان كمية الكاز المجهزة شهريآ بلغت (10.610 1 انتر / شهر). اما بالنسبة لنوع المشتركين في خدمة المولدة الكهربائية فقدا وضح لنا جدول (7) ان الدور السكنية احتلت اعلى نسبة (90\%) بو اقع (81) مولدة ثم تليها الأنشطة التجارية بواقع (9) مولدات كهربائية وبنسبة مئوية وصلت الم (10) (10) . اما فيما يخص جدول (8) الذي يوضح ان اعلى نسبة للمستفيدين من خدمة المولدات الكهربائية وصل (44.5\%) لفئة (200) مشترك بواقع (40) مولدة، ثم فئة (150) مشترك بعدد (25) مولدة وبنسبة مئوية بلغت (27.8\%) فيما جاءت فئة (250) مشترك فأكثر بالمرتبة الثالثة وبنسبة مئوية (166.6) بواقع (15) مولدة كهربائية فيا حلت فئة (100) مشترك بالمرتبة الأخيرة وينسبة مئوية وصلت (11.1\%) بواقع (10) مولدات أي ان نسبة اكثر من (17٪) من المشتركين ضمت فئة (200-150)مشترك أي ان سعة المولدات اغلبها متوسطة . يوضح لبنا جدول (9) ان اعلى نسبة لمعدل التشغيل اليومي للمولدة وصل (36.6\%٪) لفئة (12 ساعة) بواقع (3 3 ) مولدة كهربائية من حجم العينة المختارة، تليها نسبة (33.4\%٪) لفئة (15 ساعة فأكثر ) بعدد (3 ) مولدة، فيها جاءت فئة (10 ساعة) بالمرتبة الأخيرة والثالثة بواقع (27 ) مولدة وبنسبة مئوية (30٪) . اما فيما يتعلق بجدول (10) الذي يختص بأجابات التسأول عن عدد الامبيرات المعطات لكل مشترك فقد تباينت الأجابات حسب حجم العائلة وحسب القدرة الأقتصادية للعائلة فضلاً عن تغير عدد الأمبيرات المسحوبة من فصل لأخر حيث تزداد في فصل الصيف الى حد الضعف عن بعض العوائل المتمكنة اقتصاديا بسبب حر الصيف اللاهب وتقل الأمبيرات المسحوبة عند العوائل ذات الدخل المحدود ،فمن خلال خرجات الجدول نجد ان (1.14\%) من حجم العينة هم من أصحاب فئة (6امبير) بعدد (37) مولدة كهربائية لأسباب انفة الذكر فضلاً عن انشطار العوائل والأستقلالية داخل المنزل الواحد بين الأخوة ـ فيها جاءت فئة (5 ) امبير بالمرتبة الثانية بنسبة مئوية (2.3.3\%) بعدد (29) مولدة اما فئة (14 أمبير) حلت بالمرتبة 
الثالثة بواقع (18) مولدة وبنسبة (20٪) فيها جاءت فئة (3/مبير) بالمرتبة الأخيرة بنسبة (6.6\%)وبواقع (6)

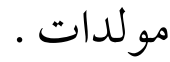

اما فيما يخص جدول (11) و الذي يتضمن الأجابات عن التساؤل بها يخص كمية المياه المستهلكة يومياً لتشغيل المولدة يومياً مقاسة باللتر فقد اختلفت الأجابات من مولدة المى أخرى تبعاً لأختلاف الحجم K.V وحسب الفصل من السنة. فكلم) كانت المولدة ذات قدرة تشغيلية كبيرة كلما زاد حجم الأستهلاك للماء اكبر سواء لغرض التبريد او الغسل والأدامة ولأستخدامات الأخرى، كذلك تختلف كمية المياه المستهلكة من فصل الى اخر حيث تزداد فيلا فصل الصيف بفعل ارتفاع درجات الحرارة وزيادة التبخر من احو اض التبريد والعكس صحيح ، ومن خلال معطيات جدول (11)يلاحظ استئثار فئة (1000لتر فأكثر/يوم) بالنسبة الأكبر من الأجابات بنسبة مئوية (35.63\%) بواقع (32 ) مولدة ،فيا حصلت فئة (50 75 لتر/ يوم) في المرتبة الثانية بواقع (27) مولدة وبنسبة المئوية (30\%). فيها جاءت فئة (500-0 500 لتر / يوم) بالمرتبة الثالثة والرابعة بواقع (23 ) و(8 ) مولدة ونسبة مئوية (5.5 25\%)

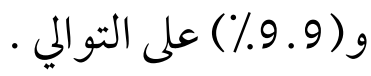
اما فيما يتعلق بسعر الأمبير الواحد والذي يوضحه جدول (12 ) فهناك تباين واضح بسعر الأمبير الواحد وهذا يعتد على جملة عو امل منها طول فترة التشغيل بسبب طول فترة انقطاع التيار الكهربائي الوطني وهذه مشكلة قديمة تعاني منها مدينة الرمادي وخاصة عند زيادة الحمولة في فصل الصيف فترة الذروة حيث وصل سعر الأمبير الواحد في الفترة السابقة من (25-20) الف دينار للأمبير الواحد عند تشغيل المولد فترة (24ساعة) ليل نهار اما في الفترة الحالية فقد اعتمدت شعبة متابعة المولدات على نظام العداد اليومي أي احتساب ساعات التشغيل الفعلية مضروبة × سعر الأمبير الواحد في الساعة الواحدة وهذا خفف الشيئ الكثير على سكان مدينة الرمادي وخاصة أصحاب الدخل المحدود .فقد بينت إجابات السؤال الخاصة بسعر الأمبير ان اكثر (77\%) من الأجابات كانت محصورة بين (14 الف -15 ألف فأكثر)، (3.3 \% ) بالمية من (15 ألف فأكثر ) بواقع (39) مولدة وجاءت فئة (14) الف دينار بنسبة (34.4٪) بواقع (31) مولد فيما 
كانت نسبة فئة (12 الف دينار) (14.4) بواقع (13) مولدة، والنسبة المتبقية (7.8\%) من نصيب فئة (10 الأف دينار) ) بواقع (7) مولدات .

فيها جاء جدول (13) ليوضح أجوبة التسائل الخاصة بكلفة التشغيل ويعرف بـ(أجور عهال التشغيل ) ) وكانت هناك اربع خيارات تبدأ بأجر شهري مقداره (250.000 دينار) واقصاه (400000 4دينار) حيث تباينة إجابات أصحاب المولدات تباين واضح نسبة الى حجم المولد وعدد المشتركين فكلما كانت القدرة التشغلية K.V للمولدة كبيرة كلما زادت أجور العمال وهذا مرهون بعدد المشتركين فعليآ بالمولد أي كلم) كان عدد المشتركين اكبر زاد راتب العامل الشهري أي هناك علاقة طردية بين عدد المشتركين والراتب الشهري فضلاً عن إعطاء المشغل خط مجاناً لبيته وهذا جانب تحفيزي للعامل. ومن جدول (13) احتلت فئة (400000000 دينار) اعلى نسبة مئوية وصلت (46.4\%) بعدد فعلي (42 ) مولد وجاءت فئة (400000 35 دينار ) بالمرتبة الثانية بنسبة وعدد فعلي (36.7\%) و(33) مولدة على التوالي ،فيما حصلت فئة (30000000 3دينار ) بالمرتبة الأخيرة بنسبة مئوية (16.7\%) بواقع (15 ) مولدة . تم طرح سؤال على أصحاب المولدات والذي يوضحه جدول (14 ) حول إمكانية تزويد أصحاب المولدات بجادة (الكاز) من قبل الحكومة مشروط بشروط بتخفيض سعر الأمبير ،وكانت الأجابة (55) مولدة (بنعم) أي ما يعادل (3.38\%) من حجم العينة المدروسة فيما كانت (16.7\%٪) من حجم العينة رافضة لمقترح بواقع (15) مولدة .

تم توجيه سؤال المى أصحاب المولدات مفاده: هل ان المولدة محورة ؟ ام مصممة اصلآ لهذا الغرض .وقبل ألأجابة عن هذا السؤال .اغلب مولدات مدينة الرمادي خاصة والعراق عامة كانت محورة في بداية ازمة الكهرباء وتجاهل واضح من قبل الجهات الحكومية في معالجة مشكلة الكهرباء والتي تعتبر مشكلة ازلية منذ ثمانيات القرن الماضي وانشغال البلد بالحروب وتبعتها ظروف الحصار القاسي ومن تواصل مسلسل الدمار والحروب بعد 2003 عند احتلال البلد ،تم استبدال جميع المولدات المحورة وخاصة بعد تنشيط الحركة التجارية للبلد لذلك جاءت اغلب إجابات جدول (5) (نعم) بنسبة (00\%) بواقع (81) مولدة فيا كانت 
إجابات (لا) بو اقع (9) مولدات وبنسبة (10\%) ـ اما فيا يتعلق بتحليل إجابات جدول (16) والذي تضمن السؤال التالي هل ان المولدة الكهربائية محورة ؟ فأجاب (20\%) من حجم العينة ب (نعم) بواقع (18)مولدة فيا كانت الأجابة ب (لا) (2 7) مولدة وبنسبة وصلت (80\%)من حجم العينة المدروسة .اما ما يخص مشاكل المولدة المحورة اكثر من حيث التشغيل بينها جدول (17)فكانت إجابة (8 7 ) من أصحاب المولدات (نعم )و (12 )إجابة (لا) مشكلة بنسبة مئوية (86.6\%) و (13.4\%) على التوالي من حجم العينة المدروسة.

جدول (8)سعة المولدة الكهربائية K.V

\begin{tabular}{|c|c|c|c|c|c|}
\hline الجموع & $500 \mathrm{~K} . \mathrm{V}$ & $400 \mathrm{~K} . \mathrm{V}$ & 350 K.V & $250 \mathrm{~K} . \mathrm{V}$ & $\begin{array}{c}\text { قدرة المولدة } \\
\text { K.V }\end{array}$ \\
\hline 90 & 37 & 24 & 17 & 12 & العدد \\
\hline$\% 100$ & 41.1 & 26.7 & 18.9 & 13.3 & $\%$ \\
\hline
\end{tabular}

جدول (9) نوع المستفيدين من خدمة المولدات الكهربائية

\begin{tabular}{|c|c|c|c|c|c|}
\hline الجموع & اخرى ال اخر & صناعي & تجاري & سكني & نوع الأستعمال \\
\hline 90 & ----- & ----- & 9 & 81 & العدد \\
\hline$\% 100$ & ----- & ----- & 10 & 90 & $\%$ \\
\hline
\end{tabular}

جدول (10) عدد المشتركين في خدمة المولدة الكهربائية

\begin{tabular}{|c|c|c|c|c|c|}
\hline المجموع & مشترك 250 فأكثر & مشترك 200 & مشترك 150 & مشترك 100 & فئات الأشتراك \\
\hline 90 & 15 & 40 & 25 & 10 & العدد \\
\hline$\% 100$ & 16.6 & 44.5 & 27.8 & 11.1 & $\%$ \\
\hline
\end{tabular}


جدول (11 )معدل ساعات التشغيل اليومي للمولدة الكهربائية

\begin{tabular}{|c|c|c|c|c|c|}
\hline الجموع & ساعة 15 فأكثر & ساعة 12 & ساعة 10 & ساعة 7 & عدد ساعات \\
\hline 90 & 30 & 33 & 27 & ----- & العدد \\
\hline $100 \%$ & 33.4 & 36.6 & 30 & ----- & $\%$ \\
\hline
\end{tabular}

$$
\text { جدول (12 ) معد الوحدات (الأمبيرات) المعطى لكل مشترك }
$$

\begin{tabular}{|c|c|c|c|c|c|}
\hline الجموع & 6 أمبير & 5 & 4 أمبير & 3 أمبير & عدد الامبيرات \\
\hline 90 & 37 & 29 & 18 & 6 & العدد \\
\hline$\% 100$ & 41.1 & 32.3 & 20 & 6.6 & $\%$ \\
\hline
\end{tabular}

\begin{tabular}{|c|c|c|c|c|c|}
\hline الجموع & 1000لتر فأكثر & 750نر/ /يوم & 500/تتر/يوم & 250نتر/يوم & عدد اللترات \\
\hline 90 & 39 & 27 & 23 & 8 & عدد المولدات \\
\hline$\% 100$ & 35.6 & 30 & 25.2 & 8.9 & $\%$ \\
\hline
\end{tabular}

\begin{tabular}{|c|c|c|c|c|c|}
\hline الجمموع & ألف فأكثر 15 & ألأف دينار 14 & الأف دينار 12 & الأف دينار 10 & سعر الأمبير الواحد \\
\hline 90 & 39 & 31 & 13 & 7 & عدد المولدات \\
\hline$\% 100$ & 43.3 & 34.5 & 14.4 & 7.8 & $\%$ \\
\hline
\end{tabular}




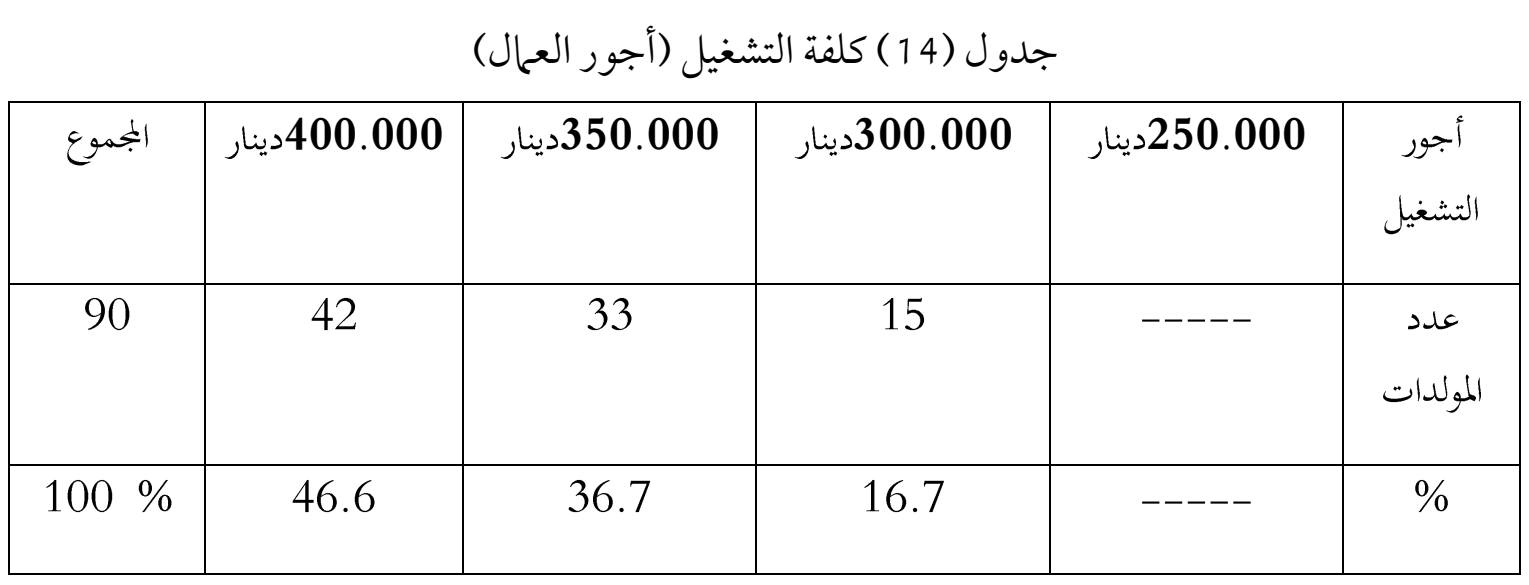

\begin{tabular}{|c|c|c|c|}
\hline الجمموع & لا أوافق & نعم موافق & هل توافق \\
\hline 90 & 15 & 75 & عدد المولدات \\
\hline$\% 100$ & 16.7 & 83.3 & $\%$ \\
\hline
\end{tabular}

جدول (16 ) المولدة الكهربائية مصممة اصلآ لمذه الخدمة

\begin{tabular}{|c|c|c|c|}
\hline المحموع & ل & نعم & هل مصممة اصلآ للتوليد \\
\hline 90 & 9 & 81 & عدد المولدات \\
\hline$\% 100$ & 10 & 90 & $\%$ \\
\hline
\end{tabular}

جدول (17 ) هل المولدة محمورة

\begin{tabular}{|c|c|c|c|}
\hline الجموع & ل & نعم & هل المولدة محمورة \\
\hline 90 & 72 & 18 & عدد المولدات \\
\hline$\% 100$ & 80 & 20 & $\%$ \\
\hline
\end{tabular}


جدول (18) مشاكل المولدة الكهربائية المحورة اكثر من حيث التشغيل

\begin{tabular}{|c|c|c|c|}
\hline الجمموع & كلا & نعم & هل توجد مشاكل \\
\hline 90 & 12 & 78 & عدد المولدات \\
\hline$\% 100$ & 13.4 & 86.6 & $\%$ \\
\hline
\end{tabular}

\section{ثانيًا : تحليل الأستبـانة الثانية والخاصة بسكان مدينة الرمادي}

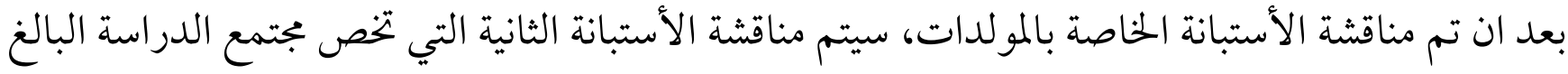
عددهم (46519) نسمة لعام (2019)، تم توزيع (400) استمارة استبيان تضمن (18) سؤال ، ونظرآ لكثرة العوائل المشمولة بالدراسة فقد واجه الباحث صعوبة في التوزيع بسبب الظروف الأمنية وصعوبة التنقل بحرية لذا جعلت توقفات عديدة بسير انجاز البحث مما تطلب مضاعفة الجهد لأنجازه ، فمن خلال جدول (18) الذي يختص بنوع الوحدة السكنية المشغولة في مدينة الرمادي ،اذ بلغت اعلى نسبة دار ذات الطابقين (7.5\%)بعدد (190) دار ،فيها جاءت نسبة دار ذات الطابق الواحد بالمرتبة الثانية بنسبة فعلية (2.2.2\%) بواقع (89)دار اما المشتمل والشقة السكنية جاءت بنسب(20.3\%) و (10\%) وبواقع (81) و (40) (40) مشتمل وشقة على التوالي كما يكشف لنا جدول (19 ) مسح للحالة الأجتماعية لسكان مدينة الرمادي ، حيث تبين ان (64\%٪) من حجم العينة مفتوح بواقع (256 )متزوج و(18.7\%)اعزب بواقع (5 75 )شخص فيما كانت النسب الباقية (50.5 \%) و(6.8\%) ارمل ومطلق على التوالي ،وهذا يعطي مؤشر وواضح على زيادة استهلاك وحدات كهربائية (امبيرات) فيما يولد ضغظ على عمل المولدات الكهربائية . اما فيما يخص جدول (20) والذي يوضح نسبة انشغال الوحدة السكنية من الأشخاص نلاحظ هناك ارتفاع اعدا الأفراد بالوحدة السكنية الواحدة وذلك لصعوبة شراء منزل مستقل فضلآ عن ارتفاع أسعار الأيجارات لذلك تضطر تسكن عائلتين او ثلاث في الوحدة السكنية الواحدة ،وهذا ما تؤكده استحارة الأستبيان الموضحة 
في ج 0 دول (20 ) حيث بين اعلى نسبة مئوية فئة (1 أفر اد فأكثر) وصلت ( 7.57 \%) بعدد(230 ) عائلة وتليها فئة (8) فرد نسبة (7.7.2\%) بواقع (115) عائلة ،فيها جاءت فئة (7 فرد) و (6فرد) بنسبة (8.8\%) و (5.5\%) بواقع (35) و(20) ) عائلة على التو الي . اما جدول (21 ) بين عدد الغرف في الوحدة السكنية الواحدة في مدينة الرمادي حيث نلاحظ ارتفاع نسبة عدد الدور السكنية التي تظم اربع و خمس غرف فأكثر بسبب ارتفاع أسعار العقار والأيجار ، لذك اتجه الكثير من العوائل المى تحويل الحديقة المنزلية المى غرف ملحقة بالبيت إضافة المى تحويل غرفة الأستقبال الى غرفة نوم والأكتفاء بغرفة الهول للضيوف وهذا ما أكدته الدراسة الميدانية حيث نلاحظ (5.75\%) من العينة المدروسة ذات خمس غرف فأكثر بعدد فعلي (223)وحدة سكنية ،فيها جاءت فئة (4غرف) بالمرتبة الثانية بنسبة (34\%)من الدور السكنية ،فيما جاءت الدور السكنية ذات (3غرف) بالمرتبة الثالثة بنسبة مئوية (3.6\%) من الدور السكنية المدروسة . فيها حلت الدور ذات (2غرف) بالمرتبة الأخيرة وبنسبة مئوية (4\%) بواقع (16)من الدور السكنية المشمولة بالدراسة .وبين الجمدول (22) ان معدل دخل الأسرة في مدينة الرمادي متباين نوع ما ـفكانت اعلى نسبة هي فئة (40 45 ألف دينار) ب (30\%) بواقع (120) أسرة فيما جاءت فئة (300 350 ألف دينار) بالمرتبة الثانية بنسبة (25.2\%) عائلة من مجتمع الدراسة فيها حصلت فئة (50 50 الف دينارفأكثر) بالمرتبة الثالثة بنسبة (25\%) وفئة (250 ألف دينار) بالمرتبة الأخيرة بنسبة( 19.5٪) بو اقع (100) و (78) اسرة على التوالي ، وهذا يعطي مؤشر واضح على تأثير هذه الخدمة على دخولهم الشهرية اذ أصبحت تكاليف أجور المولد الكهربائي تدفعها تلك العو ائل عبئآ مضافآ ساعد على تدهور مستو اهم المعيشي خاصة أصحاب الدخل المحدود ـ. وفي جدول (23) الخاص بمعدل ما تنفقه العائلة في مدينة الرمادي كأجور للمولدة الكهربائية ، حيث تبين ان اعلى معدل انفاق للعائلة شهريآ على المولدة الكهربائية وصل (45 ألف دينار) لعدد (154) عائلة وبنسبة (38.5\%) ثم فئة (5 5 ألف دينار) بعدد (98 )عائلة وبنسبة (24.5\%) ،وجاءت فئة (5 3 ألف دينار) بالمرتبة 
الثالثة بنسبة (23٪)وبعدد(2 9 وعائلة فيا حصلت فئة (25 ألف دينار)بالمرتبة الأخيرة بنسبة (14٪)وبعدد (56) عائلة .

فييا جاء جدول (24) الخاص بعدد الأمبيرات الكهربائية المستهلكة لكل اسرة في مدينة الرمادي ، كانت اعلى نسبة (39.5 \%) لفئة (16 امبير فأكثر) بعدد (158 ) أسرة فيما جاءت فئة العوائل التي تستهلك (5 أمبير) بالمرتبة الثانية بنسبة (29.8\%)وبواقع (119) أسرة ،وحلت فئة (4)،(3)أمبير بالنسب الباقية (78.7\%)و (12\%) بواقع (5 5 )،(48 ) أسرة على التوالي . وهذه الوحدات الكهربائية متذبذبة صعودآ أو نزول حسب فصول السنة حيث تزداد في فصل الصيف وتقل في فصل الشتاء وفي تحليل بيانات جدول (25 ) الخاص بعدد الأجهزة الكهربائية التي تعمل من ضمن تيار المولدة الكهربائية ،جاءت الأجابات متابينة متباينة ومختلفة من عائلة المى أخرى وهذا التباين يعتمد بالدرجة الأساس على عدد العوائل التي تسكن ضمن الوحدة السكنية الواحدة كما نوهنا في الفقرات السابقة وتعتمد على الوضع المادي للأسرة لهذا جاءت الأجابات خختلفة حيث وصلت نسبة الأسر التي تشغل (6أجهزة ) في المرتبة الأولى (2.2\%٪) بواقع (169 )عائلة اجابت بذلك .فيها جاءت العوائل التي تشغل (5أجهزة ) بنسبة (28\%) من حجم العينة المدروسة بواقع (112) أسرة ،أما الأسر التي تشغل (4أجهزة) شكلت نسبة (19.2\%) بواقع (7 7 ) أسرة بين لنا جدول (26) المسافة التي تبعد او تفصل بين المولدة الكهربائية والوحدة السكنية ، وهو معيار تخطيطي فمن خلاله نحدد مستوى التلوث الضوضائي الذي تعاني منه الأسر خاصة القريبة من المولدات ،حيث جاءت اعلى نسبة مسافة (100م)بنسبة (20.2 \%) وبعدد( 101 م) أسرة أجابت بهذا السؤال بها وصلت إجابة (8 8 اسرة بأنها ضمن فئة (200)متر وشكلت نسبة (24.5٪) أي ان حوالي (4.4\%٪)من سكان من مدينة الرمادي تقع ضمن مديات التلوث الضوضائي للفئتين (200-100 10) بواقع

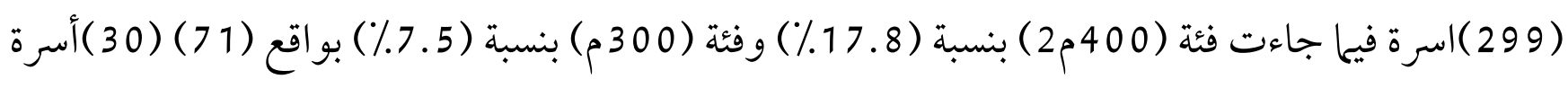
على التوالي ،مما يعني عدم وجود معيار ثابت لبعد المولدة عن الوحدات السكنية . 
وبين لنا جدول(27) الذي يتمحور حول مدى ملائمة موقع المولد الكهربائي بالنسبة للدور السكنية ،فكانت إجابة (260)ب (كلا) وبنسبة (65\%) وكان موقع المولدة ملائم بشكل تقريبي بنسبة (20\%) ولعدد (80) عائلة وكانت الأجابة (نعم)بنسبة (15\%) وبعدد (60) عائلة وهذا يعني وضع المولدات وتوزيعها لا يجضى برضى سكان مدينة الرمادي لأسباب سيتم ذكرها لاحقآ فيما بعد تتعلق بمستوى الضوضاء والغازات والأبخرة المنبعثة منها ،فيها فسر جدول لنا جدول (28) مدى تأثير ضجيج المولدات الكهربائية على سكان مدينة الرمادي فضلا عن الغازات والروائح الناتجة من احتراق الوقود فكانت إجابة (198 )عائلة كانت عالية او شديدة التلوث وبنسبة (9.5 4\%) من حجم العينة المدروسة ،اما فئة (متوسطة التلوث)جاءت بنسبة (36.5\%) واخيرآ(قليلة التلوث) بنسبة(14\%) وبواقع (146 ) (569 )عائلة على التوالي . وصول مدى تأثر السكان بالضجيج فكانت الأجابات موضحة في جدول (29 ) فكانت الأجابة ( 230 )عائلة بكلمة (نعم)ونسبة (80\%) وتليها إجابة (80) عائلة بكلمة (لا) وبنسبة (20\%) وهذا يدل على وجود نسبة كبيرة من الملوثات تزعج سكان المدينة سواء اكانت أصوات او غاز ات وهذا ما يتم تأكيده لاحقآ. وجاء جدول (30 ) ليحدد درجة المفاضلة بين ان يكون هناك مولد كهربائي واحد وبسعة كبيرة يغطي كل مدينة الرمادي او معظم اجزائها فكانت نسبة الأجابة (نعم) (89٪) من حجم العينة المدروسة بواقع (36 56 )اسرة فيم|(11\%) من حجم العينة كانت اجابتهم (كلا) بواقع (4 4 )عائلة .وبين لنا جدول (1 3 ) الذي يوضح رغبة السكان بتجهيزهم بالتيار الكهربائي من قبل الدولة وكانت (0 9\%) من الأسر تؤيد ذلك بأن يكون التجهيز من قبل الدولة بو اقع (30 3أسرة) فيا (40) عائلة رفضت هذا المقترح مشكلة نسبة مئوية (10) وبسبب ألأنقطاع المستمر في التيار الكهربائي وعجز الجهات الحكومية على حل هذه المشكلة ،تم طرح سؤال مفاده هل ترغب ان تكون هناك استثلارات في مجال الطاقة ،فتبين ان هناك نسبة كبيرة من سكان مدينة الرمادي ترغب بالأستثلمر في هذا القطاع للتخلص من هذه المشكلة لذا وصلت نسبة الموافقة (60٪) بواقع (280) اسرة مقابل (30\%) من حجم العينة رفضت الفكرة بواقع (120 )أسرة كما في جدول (32). 
اما معطيات جدول (33)فبينت أن (5.5 67\%) من سكان مدينة الرمادي نفضل ان تكون ملكية المولدات الكهربائية تابعة للقطاع العام بواقع (0 72 )عائلة (24\%)من حجم العينة ذهبت رغبتهم بأتجاه القطاع المختلط بو اقع (9 7 ) عائلة فيها كانت إجابة (3 3 ) عائلة نحو القطاع الخاص مشكلة بنسبة (2.28\%) من حجم العينة.

جدول (19 ) نوع الوحدة السكنية

\begin{tabular}{|c|c|c|c|c|c|}
\hline الجمموع & شقة سكنية & مشتمل & دار طابقين & دار طابق واحد & نوع الوحدة \\
\hline 400 & 40 & 81 & 190 & 89 & العدد \\
\hline$\% 100$ & 10 & 20.3 & 47.3 & 22.2 & $\%$ \\
\hline
\end{tabular}

جدول (20 يمثل الحالة ألأجتماعية لسكان الوحدة السكنية

\begin{tabular}{|c|c|c|c|c|c|}
\hline الجموع & ارمل & مطلق & متزوج & اعزب & الحالة الأجتماعية \\
\hline 400 & 42 & 27 & 256 & 75 & العدد \\
\hline$\% 100$ & 10.5 & 6.8 & 64 & 18.7 & $\%$ \\
\hline
\end{tabular}

جدول (2 2 ) عدد افراد الأسرة في الوحدة السكنية

\begin{tabular}{|c|c|c|c|c|c|}
\hline الجمموع & 10 فرد فأكثر & 8 فرد & 7 فرد & 6 فرد & عدد افراد ألأسرة \\
\hline 400 & 230 & 115 & 35 & 20 & عدد العوائل \\
\hline$\% 100$ & 57.5 & 28.7 & 8.8 & 5 & $\%$ \\
\hline
\end{tabular}




\begin{tabular}{|c|c|c|c|c|c|}
\hline الجمبوع & غرف فأكثر 5 & غرف 4 & غرف 3 & غرف 2 & عدد الغرف في \\
\hline 400 & 223 & 136 & 25 & 16 & عدد الدور \\
\hline$\% 100$ & 55.7 & 34 & 6.3 & 4 & $\%$ \\
\hline
\end{tabular}

\begin{tabular}{|c|c|c|c|c|c|}
\hline المجموع & ألف دينار 550 & ألف دينار 450 & ألف دينار 350 & ألف دينار 250 & مقدار الدخل \\
\hline 400 & 100 & 120 & 1.2 & 78 & عدد ألأسر \\
\hline$\% 100$ & 25 & 30 & 25.5 & 19.5 & $\%$ \\
\hline
\end{tabular}

جدول ( 24 ) معدل ما تنفقه ألأسرة كأجور على المولدات الكهربائية

\begin{tabular}{|c|c|c|c|c|c|}
\hline الجمجوع & ألف دينار 55 & ألف دينار 45 & ألف دينار 35 & ألف دينار 25 & مبلغ ألأجور \\
\hline 400 & 98 & 154 & 92 & 56 & عدد ألأسر \\
\hline$\% 100$ & 24.5 & 38.5 & 23 & 14 & $\%$ \\
\hline
\end{tabular}

جدول (5 2 ) عدد الوحدات (الأمبيرات) الكهربائية التي تستهلكها الأسرة الواحدة

\begin{tabular}{|c|c|c|c|c|c|}
\hline الجموع & أمبير 6 & أمبير 5 & أمبير 4 & أمبير 3 & عدد الأمبيرات \\
\hline 400 & 158 & 119 & 75 & 48 & عدد ألأسر \\
\hline$\% 100$ & 39.5 & 29.8 & 18.7 & 12 & $\%$ \\
\hline
\end{tabular}




\begin{tabular}{|c|c|c|c|c|c|}
\hline المجموع & جهاز & جهاز 6 & جهاز 5 & جهاز 4 & عدد ألأجهزة \\
\hline 400 & 42 & 169 & 112 & 77 & عدد العوائل \\
\hline$\% 100$ & 10.6 & 42.2 & 28 & 19.2 & $\%$ \\
\hline
\end{tabular}

\begin{tabular}{|c|c|c|c|c|c|}
\hline البجموع & متر فأكثر 400 & متر 300 & متر 200 & متر 100 & المسافة/م \\
\hline 400 & 71 & 30 & 98 & 201 & عدد ألأسر \\
\hline$\% 100$ & 17.8 & 7.5 & 24.5 & 50.2 & $\%$ \\
\hline
\end{tabular}

جدول ( 28 ) مدى ملائمة موقع المولدة بالنسبة للوحدة السكنية

\begin{tabular}{|c|c|c|c|c|}
\hline المجموع & تقريباً & كلا & نعم & مدى الملائمة \\
\hline 400 & 80 & 260 & 60 & عدد ألأسر \\
\hline$\% 100$ & 20 & 65 & 15 & $\%$ \\
\hline
\end{tabular}

\begin{tabular}{|c|c|c|c|c|}
\hline الجمموع & عالية التلوث & متوسطة التلوث & قليلة التلوث & نسبة التلوث \\
\hline 400 & 198 & 146 & 56 & عدد ألسر \\
\hline$\% 100$ & 49.5 & 36.5 & 14 & $\%$ \\
\hline
\end{tabular}




\begin{tabular}{|c|c|c|c|}
\hline الجموعوع & لا & نعم & هل يؤثر \\
\hline 400 & 80 & 320 & عدد ألأسر \\
\hline$\% 100$ & 20 & 80 & $\%$ \\
\hline
\end{tabular}

جدول (1 3 ) هل تفضل ان تكون مولدة كبيرة تغطي المدينة بالكامل

\begin{tabular}{|c|c|c|c|}
\hline الجمموع & لا & نعم & هل تفضل ؟ \\
\hline 400 & 44 & 356 & عدد ألأسر \\
\hline$\% 100$ & 11 & 89 & $\%$ \\
\hline
\end{tabular}

جدول (2 3 ) هل تفضل ان يكون التجهيز من قبل الدولة

\begin{tabular}{|c|c|c|c|}
\hline الجموع & ل & نعم & هل تفضل؟ \\
\hline 400 & 40 & 360 & عدد ألأسر \\
\hline$\% 100$ & 10 & 90 & $\%$ \\
\hline
\end{tabular}

جدول (33 ) هل تفضل ان تكون هناك استثمارات في الطاقة

\begin{tabular}{|c|c|c|c|}
\hline الجمدوع & ע & نعم & هل تفضل؟ \\
\hline 400 & 120 & 280 & عدد ألأسر \\
\hline$\% 100$ & 30 & 70 & $\%$ \\
\hline
\end{tabular}


جدول (34 ) هل تفضل ان تكون ملكية المولدة تابعة الى

\begin{tabular}{|c|c|c|c|c|}
\hline الجموع & القطاع المختلط & القطاع الخاص & القطاع العام & نوع القطاع \\
\hline 400 & 97 & 33 & 270 & عدد ألأسر \\
\hline$\% 100$ & 24.3 & 8.2 & 675 & $\%$ \\
\hline
\end{tabular}

\section{محور الضوضاء وتلوث الهواء بالغازات}

بعد ان تم مناقشة استحارة ألأستبيان الخاصة بأصحاب المولدات وأصحاب الدور السكنية من سكنة مدينة الرمادي، وقد حصلنا على الكثير من المعلومات والبيانات ميدانياً بواسطة الأستبانات التي غطت جوانب عديدة فيها يتعلق بالبحث، ولزيادة الرصانة العلمية للبحث العلمي سيتم مناقشة التلوث الضوضائي والهوائي ميدانياً بأستخدام جهاز (Sound Level Meter) (SVA955) وقد تم اختيار (8) مواقع متنوعة الأستعمال (تجاري-صناعي -سكني-خدمي) لتحديد بها مستويات الأصوات ومقارنتها مع المحددات البيئية المسموح بها ولكل استعمال ، فضلا عن تلوث الهو اء عن طريق قياس ثلاث عناصر مهمة ولمناطق مختلفة مع اهم المواد العالقة ومن تحليل معطيات جدول (34 ) الخاصة بمستويات الضوضاء للمواقع الموجودة ، تبين أن المنطقة التجارية مستويات التلوث الضوضائي بها محصور بين (3.4 73.13 7ديسبل) اعلاها في (شارع عمر وشارع الثيلة )بمستوى ضوضائي (3.4 7ديسبل) و(شارع 100،و 5 كيلو) بمستوى ضوضائي (13.1 7ديسبل) بسبب وجود اعداد كبيرة من المولدات الكهربائية فضلا عن السيارات بأنواعها وعند مقارنتها بالمحدودات البيئية نجدها اعلى من الحد المسموح به للمناطق التجارية الذي حددته المنظمات العالمية والبالغ (5 6 ديسبل) اما فيا يخص الجاني الخدمي الذي يمثله شارع جامع الدولة والقطانة فكان مستوى الضوضاء عالي فقد وصل (7 7 د ديسبل) عن الحد المسموح به بيئياً. فيما انحصرت مستويات الضوضاء في المناطق السكنية بين (59.80.1 ديسبل) اقلها في شارع حي الضباط بمستوى ( 79.8 ديسبل) واعلاها في (شارع ناظم الورار ) بمستوى ضوضائي (10.1 7ديسبل) وعند مقارنتها بالمحددات البيئية لمستويات الصوت في المناطق السكنية والبالغ 
(5 5 ديسبل) نجدها تفوق المحدد بكثير وهذا ما وضحته استحارة الأستبيان في جدول (29 ) حيث كانت نسبة انزعاج سكان المدينة (80\%)من سكان المدينة وبو اقع (20 320 عائلة أبدت انزعاجها من أصوات المولدات العالية ، فيا كانت مستويات الضوضاء في الحي الصناعي والسير اميك والتي صنفت على انها استعهال صناعي كانت ضمن المحددات البيئية بواقع (1.06ديسبل) وهي اقل من الحد المسموح به والبالغ (0 7ديسبل) ،بصورة عامة هناك مشكاة عامة في مدينة الرمادي وهي ارتفاع مستويات الضوضاء بسبب وجود المولدات

$$
\text { التي تزعج سكان المدينة . }
$$

جدول (35) مستويات التلوث الضوضائي ولمختلف المناطق في مدينة الرمادي

\begin{tabular}{|c|c|c|c|c|}
\hline الأحداثيات & بالديسبل $\quad$ البيئي & مستوى الصوت & تصنيف & موقع القياس \\
\hline $\begin{array}{l}N=33.425424 \\
E=43.327503\end{array}$ & 65 & 73.4 & بتحارية & 1-شارع عمر -الثيلة \\
\hline $\begin{array}{l}N=33.42846 \\
E=43.30897\end{array}$ & 65 & 77.7 & خدمية & 2-شارع الدولة-القطانة \\
\hline $\begin{array}{l}N=33.413030 \\
E=43.306431\end{array}$ & 55 & 66.4 & سكنية & 3-شارع دور المخابرات- \\
\hline $\begin{array}{c}N=33.41836 \\
E=43=277442\end{array}$ & 55 & 59.8 & سكني & 4-شارع حي الضباط \\
\hline $\begin{array}{l}N=33.409179 \\
E=43=277442\end{array}$ & 55 & 79.7 & سكني & 5-شارع حي المعلمين \\
\hline $\mathrm{N}=33.409179$ & 55 & 70.1 & سكني & 6-شارع ناظم الورار \\
\hline
\end{tabular}




\begin{tabular}{|c|c|c|c|c|}
\hline$E=43.273301$ & & & & \\
\hline $\begin{array}{l}N=33.414714 \\
E=43.226265\end{array}$ & 70 & 61.0 & صناعي & 7-السيراميك $\quad$ الصناعي-شارع \\
\hline $\begin{array}{l}N=33.436276 \\
E=43.299136\end{array}$ & 65 & 73.1 & تجارية & 8-شارع100- 5 كيلو \\
\hline
\end{tabular}

\section{تلوث الهواء}

بعد اكمال اشكال فيها يتعلق بالتلوث الضوضائي ،تم اجر اء دراسة ميدانية ولمواقع خختلفة داخل مدينة الرمادي تضمنت مناطق سكنية وتجارية وخدمية بأستخدام جهازي (Casmet) و (Met1) كما مبين في الجمدول (37 ). جدول(37) المناطق الموجودة في مدينة الرمادي

\begin{tabular}{|c|c|c|c|}
\hline الأحداثيات & الموقع & أسم الموقع & رقمت \\
\hline $\begin{array}{l}N=33.436279 \\
E=43.299136\end{array}$ & مرورية & م قاطعة الثيلة - ساحة الدولفين - شارع عمر بن الخطاب & 1 \\
\hline $\begin{array}{l}\mathrm{N}=33.42846 \\
\mathrm{E}=43.30877\end{array}$ & خدمية- & تقاطع جامع الدولة الكبيربالقرب من الدوائر الحكومية & 2 \\
\hline $\begin{array}{l}N=33.425424 \\
E=43.327503\end{array}$ & سكنية & شارع الملعب - دور المخابرات & 3 \\
\hline $\begin{array}{l}N=33.413030 \\
E=43.306431\end{array}$ & خدمية- & شارع حي الضباط قرب المركز الصحي & 4 \\
\hline $\mathrm{N}=3341836$ & سكنية & حي المعلمين - شارع المستودع & 5 \\
\hline
\end{tabular}




\begin{tabular}{|c|c|c|c|}
\hline $\mathrm{E}=43.29961$ & & & \\
\hline $\begin{array}{l}N=33.428020 \\
E=43.277442\end{array}$ & مرجعة & ناظم الورار(الجانب ألأيسر) & 6 \\
\hline $\begin{array}{l}N=33409179 \\
E=43.273301\end{array}$ & صناعي- & التأميم - شارع السيراميك & 7 \\
\hline $\begin{array}{l}N=33.414714 \\
E=43.226265\end{array}$ & مرورية & 5 كيلو - شارع 100 & 8 \\
\hline
\end{tabular}

\section{نتائج قياسـات الملوثات الهوائية الغازيـة}

تبين من جدول (37) ان معدلات تراكز غاز (NO2) قد تجاوزت المحدد الوظيفي في كل مواقع القياس وقد تراوحت بين (ppm9.86) جزء بالمليون حيث كانت اعلى قراءة في موقع (3) و واقلها في موقع (1 ) ،أما ما يخص غاز (CO) نلاحظ ارتفاع واضح في قيم التركيز لسبع مواقع اعلاها في الموقع (2) بتركيز (ppm3.82) واقلها في موقع (5) بتركيز (ppm0.09) ـ وكذلك نلاحظ ان معدلات تركيز غاز الأزون (O) قد تجاوزت المحدد الوظيفي في ستة مواقع وانحصرت بين (0.01 - ppm1.16) وبشكل عام ان النتائج تعكس التأثير الو اضح لأنبعاث عو ادم المولدات ألأهلية والمركبات المتنوعة كمصادر. 


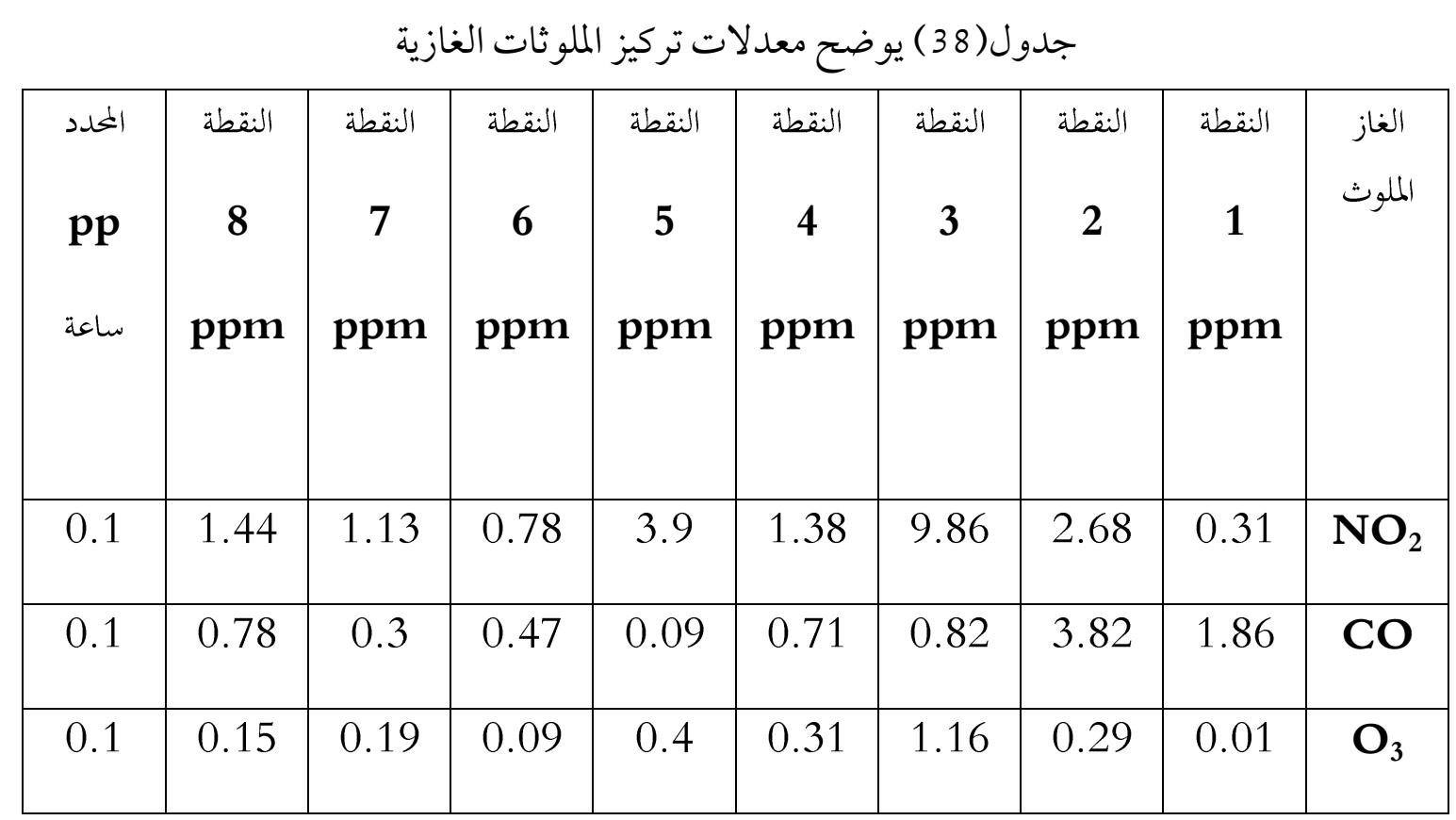

\section{حجم الدقائق العالقة:}

يقصد بالدئقيات المواد المنتشرة كافة سواء كانت دقائق صلبة ام سائلة عالقة في الهواء وتشمل الدقائق الكبيرة و الرماد المتطاير والغبار في حين تشمل الدقائق الصغيرة كلآمن الدخان والضباب والهواء الجوي وكل هذه الملوثات الكبيرة والمتوسطة الحجم والمتشابهة في الصغر تم قياسها (Tsp،pm10،pm2.5 مايكرون ) كبيرة الحجم ومتوسطة ودقيقة الحجم على التوالي.فمن خلال جدول (39 ) نلاحظ ان (TSP) تنحصر تراكيزها بين (159 - 153-83 اعلاها في الموقع (2) و اقلها في الموقع (7) اغلبها تفوق المحدد البيئي ،اما ما يخص حجم الدقائق العالقة متوسطة الحجم (pm10) فهي أيضا فاقت المحدد البيئي ولجميع المو اقع بسبب وجود المولدات الكهربائية وبأعداد كبيرة في مدينة الرمادي ،حيث سجلت المو اقع التالية (2) ،(1 ) ،(4) 288m3 (4 اكيز عالية -356-538) على التو الي • فيما كانت حجم الدقائق الصغيرة الحجم (pm2.5) كلها ضمن الحدود المسموح بها بأستثناء موقع (4) بتر كيز (64m2.5) . 
جدول (39) يوضح معدلات تركيز الملوثات الدقائقية العالقة

\begin{tabular}{|l|c|c|c|c|c|c|c|c|c|}
\hline $\mathbf{u 9 / m} / \mathbf{m}^{\mathbf{3}}$ & $\mathbf{8}$ & $\mathbf{7}$ & $\mathbf{6}$ & $\mathbf{5}$ & $\mathbf{4}$ & $\mathbf{3}$ & $\mathbf{2}$ & $\mathbf{1}$ & $\mathbf{4} 9 / \mathbf{m}^{\mathbf{3}}$ \\
& & & & & & & & & \\
& & & & & & & & & \\
\hline
\end{tabular}

النتائج والتوصيات:

النتائج:

1 - من خلال الدراسة تبين ان مدينة الرمادي تظم (3 53 مولدة) موزعة على الأحياء 2 - هناك شكاوى من سكان مدينة الرمادي بسبب أصوات المولدات وتعب بذلك ( 80٪) من حجم العينة لأن اغلب المولدات لا تحتوي على كاتم للصوت . 3- اغلب الملوثات التي تخلفها المولدات تصرف مع شبكة الصرف الصحي . 4- بينت الدراسة ان اختيار موقع المولدات جميعها لم يكن مصمم اساسآ لذذه الغاية ،وعدم وجود معيار ثابت للمساحة التي تشغلها المولدة فهي تراوحت بين (50م2 _ 100 م22) 5- من خلال الدراسة الميدانية تبين ان نسبة كبيرة من هذه المولدات تقع بالقرب من الدور السكنية والمدارس وتكون مصدر ازعاج ضوضائي وتلوثاً عال مضر آبييئة المدينة . 6 - عدم التزام أصحاب المولدات بأجر أت خفض التلوث الضوضائي عن طريق : 0 7 - أ:-عدم احاطة هذه المولدات بأسيجة من ألأشجار أو العوازل للصوت كالسندويش بنل او البلوك . 
8 - ب:-عدم وضع مخدات للأهتزاز اسفل المولدة والتي تصنع غالبآ من مو اد مطاطية خاصة حتى لا تسبب اهتزازات او احتكاكات تؤدي المى صدور الضوضاء.

9- أوضحت الدراسة ان مشاكل المولدة المحورة اكثر من مشاكل المولدة المصممة اصلاً لهذه الغاية وبدور

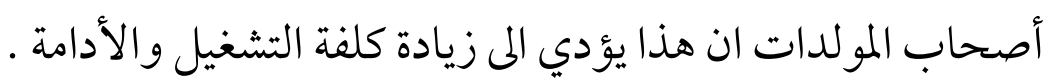

10 - بينت الدراسة ان اعلى معدل لدخل الاسرة هو اكثر من (50000)دينار شهريآ ومعدل ما تنفقه الأسرة هو اكثر من (55)ألف دينار شهريآ عدا ما ينفقونه على المولدة المنزلية وهذا يؤثر على الدخل الشهري للعائلة .

11 - نسبة كبيرة من سكان المدينة يفضلون يكون تجهيز الطاقة الكهربائية من قبل القطاع العام . 12 - كانت الأجابات بنسبة كبيرة من العوائل ان تكون ملكية المولدات الكهربائية تابعة المى القطاع العام 13 - ان نتائج المسح الميداني يمثل مؤشر اولي عن نوعية الهو اء في مدينة الرمادي فمن خلال الرصد الموقعي نلاحظ اغلب الغازات تجاوزت الحدود البيئة المسموح بها نتيجة زيادة عمل المولدات .

\section{التوصيات: - (التو}

1 - تفعيل مفهوم المراقبة البيئية لنوعية الهواء يتطلب منظومة متكاملة من محطات نوعية الهواء وألأجهزة المحمولة لغرض مو اكبة توسع ألأنشطة الصناعية والخدمية والمرورية المتنامية. 2- - على بلدية الرمادي وضع معايير وشروط فنية لمنح اجازات انشاء المولدات في المناطق السكنية. 3- ضرورة تشجيع وتنفيذ مبادرات التشجير وزيادة المساحات الخضراء لغرض تقليل تراكيز الملوثات

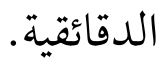

4- متابعة عمل المولدات ألأهلية وتطبيق المعالجات الموقعية الممكنة لتقليل تأثير ألأنبعاثات على المناطق

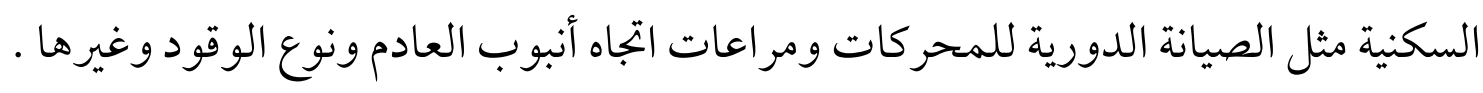


5- التزام أصحاب المولدات بأجرأت المعالجة الخاصة بتقليل التلوث الضوضائي وذلك بوضع كواتم الصوت واحاطة المولدات بسياج من مادة السندويش بنل وكذلك تشجير محيط موقع المولدة ووضع خخدات للأهتزاز تحت قواعد المحرك للتقليل من الضوضاء 6- ان تقوم دوائر البلدية بالتعاون مع دائرة البيئة بوضع ضو ابط لمواقع المولدات.

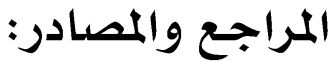

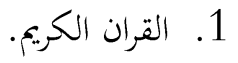

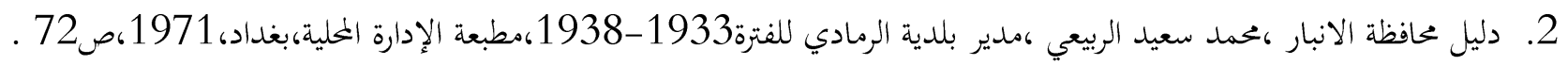

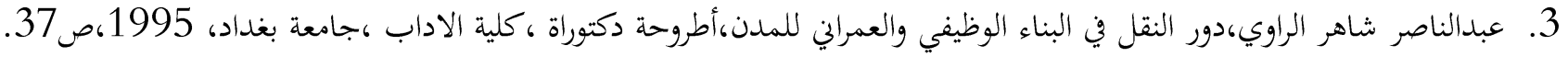

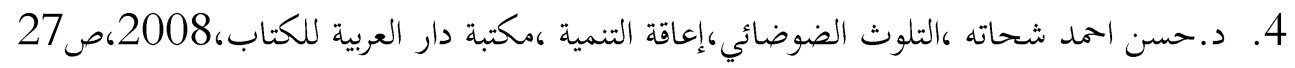

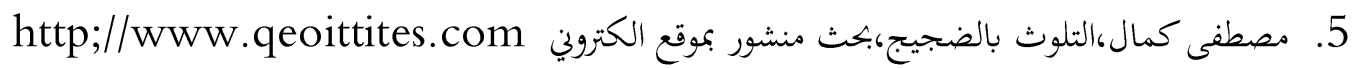

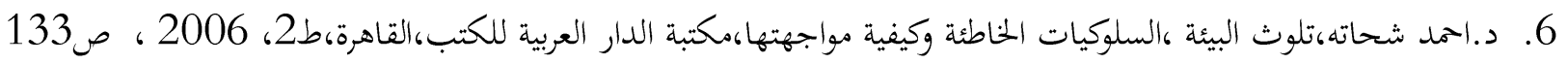

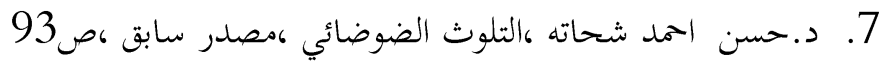

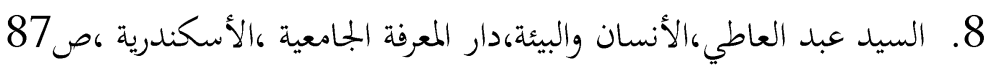

9.

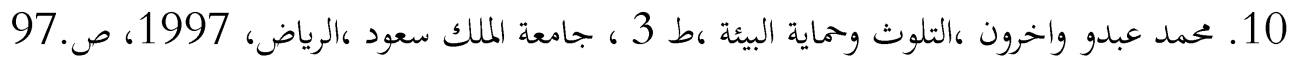

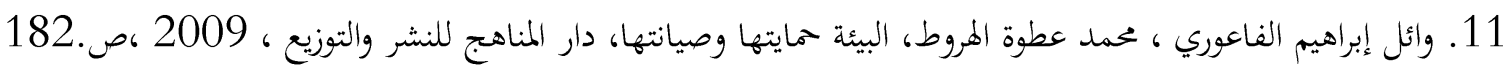




$$
\begin{aligned}
& \text { بسم الله الرحمن الرحيم } \\
& \text { جامعة الأنبار / كلية التربية للعلوم الأنساني } \\
& \text { قسم الجغرافيا } \\
& \text { م / أستبيان رقم (1) - (1) }
\end{aligned}
$$

اخي المواطن اختي المواطنة يروم الباحث القيام ببحث علمي يختص بتقديم خدمة مهمة تصب في الصالح العام وهي معرفة كمية ونوع التلوث

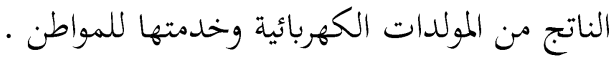
وهذه المعلومات التي تقدمها بدقة لأغراض البحث العلمي راجين تعاونكم خدمة لبلدنا العزيز والله الموفق. الباحث أ. أ.د.دصي عبد حسين

$$
\begin{aligned}
& \text { ملاحظة \تكون الأجابة بوضع علامة على اختيارك. } \\
& \text { علمآ ان الأستبيان مغلق لأصحاب المولدات الكهربائية فقط .. } \\
& \text { 1) كيف تم اختيارك لموقع المولد الكهربائي : } \\
& \text { 1 - حسب حاجة الحي السكني }
\end{aligned}
$$

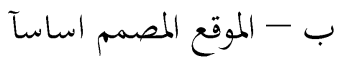

$$
\begin{aligned}
& \text { ج - تم تحوير موقع المولد } \\
& \text { 2) كم المساحة التي يشغلها المولد الكهربائي وملحقاته : } \\
& \text { i } \\
& \text { ب ب } \\
& \text { ج- } 80 \text { - } 80
\end{aligned}
$$

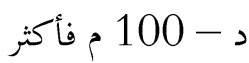

$$
\begin{aligned}
& \text { 3) موقع المولدات بالقرب من : داكتر } \\
& \text { أ - أ دور سكنية } \\
& \text { ب - مركز صحي } \\
& \text { ج - خدمات اجتماعية }
\end{aligned}
$$




$$
\begin{aligned}
& \text { أ - } 3
\end{aligned}
$$

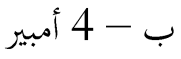

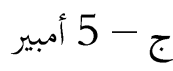

$$
\begin{aligned}
& \text { د - } 6 \text { أمبير فأكثر } \\
& \text { 11)كم هي كمية المياه المستهلكة في تشغيل المولد الكهربائي في اليوم الواحد : }
\end{aligned}
$$

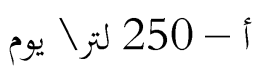

$$
\begin{aligned}
& \text { ب- - } 500 \text { لتر \يوم } \\
& \text { ج - } 750 \text { لتر \يوم }
\end{aligned}
$$

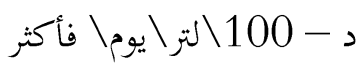

$$
\begin{aligned}
& \text { 12) سعر الأمبير من المولدة : 12 } \\
& \text { أ - } 100 \text { ألف ألف } \\
& \text { ب - } 12 \text { ألف } \\
& \text { ج - } 14 \text { ألف } \\
& \text { د - } 15 \text { ألف } \\
& \text { 13) } \\
& \text { أ - } 250000 \\
& \text { ب - } 300000 \text { دينار } \\
& \text { ج - } 400000 \text { دينار } \\
& \text { 14) بتهيز الوقود من قبل الدولة مع تخفيظ سعر الأمبير ؟ } \\
& \text { i } \\
& \text { ل } \\
& \text { 15)المولدة الكهربائية مصممة اساسأ لهذه الخدمة ؟ } \\
& \text { أ - ن } \\
& \text { ل } \\
& \text { 16)هل ان المولدة محورة ؟ } \\
& \text { أ - ن } \\
& \text { ب } \\
& \text { 17)هل ان مشاكل المولدة المحورة اكثر من حيث التشغيل ؟ } \\
& \text { أ - ن } \\
& \text { ب }
\end{aligned}
$$




$$
\begin{aligned}
& \text { بسم الله الرحمن الرحيم } \\
& \text { جامعة الأنبار \كلية التربية للعلوم الأنساني } \\
& \text { قسم الجغرافيا } \\
& \text { ? أستبيان رقم (2) }
\end{aligned}
$$

اخي المواطن اختي المواطنة يروم الباحث القيام ببحث علمي يختص بتقديم خدمة مهمة تصب في الصالح العام وهي معرفة كمية ونوع التلوث الناتج من المولدات الكهربائية وخدمتها للمواطن · لموري

وهذه المعلومات التي تقدمها بدقة لأغراض البحث العلمي راجين تعاونكم خدمة لبلدنا العزيز والله الموفق .<smiles>[AlH2][SiH3]</smiles>

أ.م.د. قصي عبد حسين

ملاحظة \ تكون الأجابة بوضع علامة على اختيارك.

$$
\text { 1 }
$$$$
\text { أ - - دار ذات طابق واحد }
$$$$
\text { ب - مار ذات طابقين }
$$$$
\text { ج - نصف دار (مشتمل ) }
$$

$$
\text { د - عمارة سكنية (شقق) }
$$

2. الحالة الأجتماعية لسكان الوحدة السكنية :

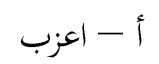

$$
\text { ب - متزوج }
$$$$
\text { ج - مطلق }
$$

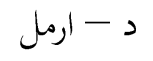

3. عدد افراد الأسرة في الوحدة السكنية :

$$
\begin{aligned}
& 5-i \\
& \text { ب - } \\
& 8-7 \\
& \text { د - } 10 \text { فأكثر } \\
& \text { 4. عدد الغرف في الوجدة السكنية : }
\end{aligned}
$$




$$
\begin{aligned}
& 2-i \\
& 3-\varphi \\
& \text { (4- } \\
& 5-\text { s }
\end{aligned}
$$

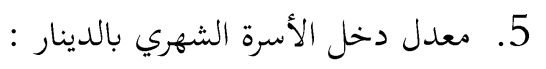

$$
\begin{aligned}
& \text { أ - } 250 \text { ألف دينار } \\
& \text { ب - } 350 \text { ألف دينار } \\
& \text { ج - } 450 \text { ألف دينار } \\
& \text { د - 250 ألف دينار فأكثر } \\
& \text { 6. معدل ما تنفقه الأسرة من أجور المولد الكهربائي : } \\
& \text { أ - } 25000 \text { دينار } \\
& \text { ب - } 35000 \text { دينار } \\
& \text { ج - } 45000 \text { دينار } \\
& \text { د - } 55000 \text { دينار } \\
& \text { 7. عدد الأمبيرات التي تستهلكها الأسرة من المولد الكهربائي : دان }
\end{aligned}
$$

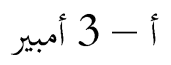

$$
\begin{aligned}
& \text { ب - } 4 \text { - } 4 \text { أمبير } \\
& \text { ج - } 5 \text { - أمبير } \\
& \text { د - } 6 \text { أمبير فأكثر } \\
& \text { 8. عدد الأجهزة الكهربائية التي تعمل ضمن تيار المولد الكهربائي : } \\
& \text { أ - } 4 \text { أجهزة } \\
& \text { ب - } 5 \text { - } 5 \text { أجهزة } \\
& \text { ج - } 6 \text { أجهزة } \\
& \text { د - } 7 \text { أجهزة منزلية } \\
& \text { 9. المسافة التي تبعد الوحدة السكنية عن المولد الكهربائي : }
\end{aligned}
$$

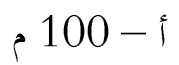

$$
\begin{aligned}
& \text { ب } \\
& \text { ج - 300- }
\end{aligned}
$$

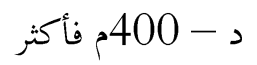

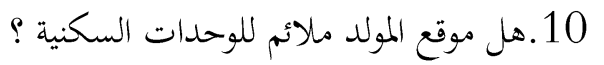




$$
\begin{aligned}
& \text { أ-نعم } \\
& \text { ب } \\
& \text { ج - تقريباً }
\end{aligned}
$$$$
\text { 11. هل هناك تأثير للمولد الكهربائي على صحة المواطن من حيث التلوث : }
$$$$
\text { أ- أ- قليلة التلوث }
$$$$
\text { ب- متوسط التلوث }
$$

$$
\text { ج - عالية التلوث }
$$

12.هل هناك تأثير على المواطن من حيث الضجيج المنبعث من المولد الكهربائي ؟

$$
\text { أ ب- أنعم }
$$

13.هل تفضل ان يكون هناك مولد كهربائي واحد بسعة كبيرة يغطي القطاع بشكل كامل ؟

$$
\text { أ أ -نعم }
$$

14.هل تفضل ان يكون هناك بتهيز مستمر من قبل الدولة للكهرباء بسعر اكبر للوحدة من المولد الكهربائي ؟

$$
\text { أ ب- بعم }
$$

15.هل تفضل ان تكون هناك شركات قطاع خاص بجهز كهرباء بشكل افضل وبمواصفات ليس لها تأثير على المناح ؟

$$
\text { أ ب- أ -نعم }
$$

16.هل تفضل ان تكون هناك استثمارات في القطاع الخناص؟

$$
\text { أ ب- أنعم }
$$

17. هل تفضل ان تكون ملكية المولدات تابعة الى :

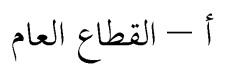

$$
\text { ب - القطاع الخاص - القطاع }
$$$$
\text { ج - القطاع المختلط }
$$ 


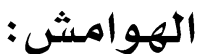

(1) علي سالم الشواورة, المدخل الى علم البيئة, عمان دار الميسرة للنشر , طبعة الاولى, 2012, ص 133 133-134.

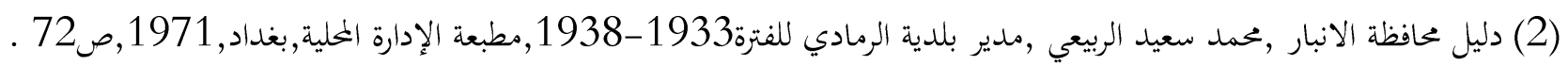

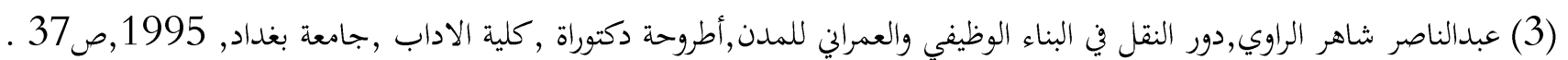

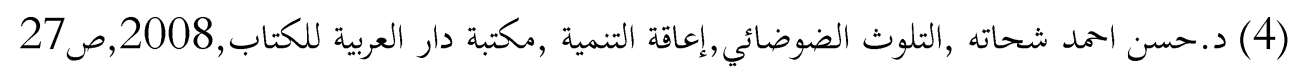

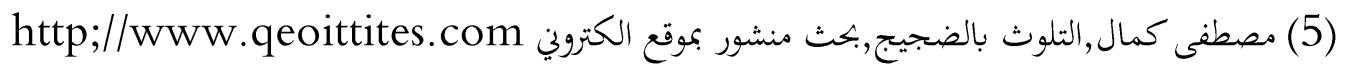

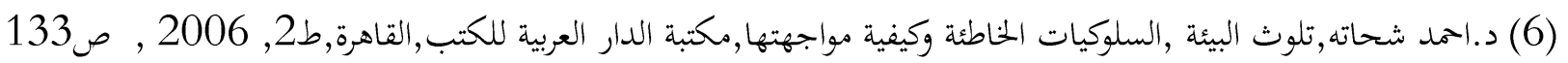

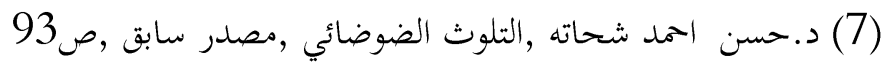

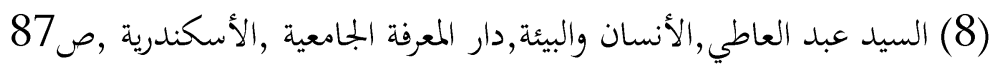

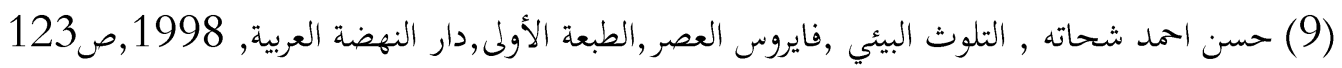

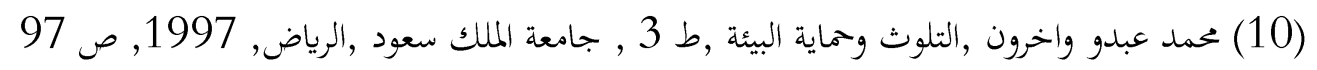

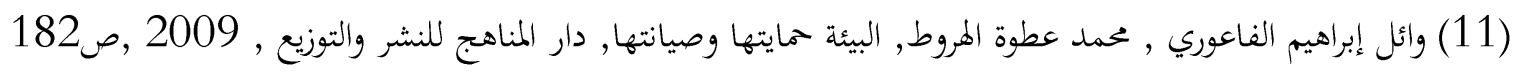

